\title{
Characterisation of 19th and 20th century Chinese paper
}

\author{
Natalie Brown ${ }^{1 *}$, Dirk Lichtblau ${ }^{2}$, Tom Fearn ${ }^{3}$ and Matija Strlič ${ }^{1}$
}

\begin{abstract}
The chemical and physical properties of 19th and 20th century Chinese papers were investigated using a variety of material characterisation methods. A reference collection of 178 Chinese papers, dating from 1799 to 1990 was used, and properties such as $\mathrm{pH}$, degree of polymerisation (DP), lignin content, and tensile strength (zero-span) were determined. Most of the papers were of approximately neutral pH, had a low lignin content and DP similar to pre-19th century European rag paper. It was found that the high inhomogeneity and the typical paper thinness affected tensile testing and as a result, a modified method for zero-span tensile strength test was developed. Using near infrared spectroscopy (NIR), proof-of-concept partial least squares (PLS) applications were developed for determination of tensile strength, pH, DP and for dating of the samples. For the latter, using post-1900 papers, the error of cross validation was 13 years. The presence of lignin was modelled using linear discriminant analysis (LDA), where the model could distinguish between high and low lignin content with $88 \%$ accuracy. Using one or multiple sheets for transmission NIR spectroscopy led to PLS results of similar quality, which was attributed to material inhomogeneity.
\end{abstract}

Keywords: Near infrared spectroscopy, Chemometrics, Non-destructive, Tensile strength, Dating, Conservation, Archives, Libraries

\section{Introduction}

Many libraries, archives and museums house significant Chinese paper collections. However, there have been limited studies into the material composition of this paper type; it has been common to focus on European papermaking practices at least in Western studies [1,2]. Compared to European paper, paper from the sino-japanese cultural realm remains relatively less known. For the purpose of this research, Chinese paper is defined as any paper originating from China.

As papermaking spread through China it became a highly competitive and regionalised practice, and papermakers relied heavily on local vegetation for raw materials. Individual recipes by local mills differed, creating a non-standardised and often secretive industry, as these recipes were not shared $[1,3,4]$. Adding to this, the end use of the paper would often determine its material properties i.e. the fibres used, amount of impurities left in the

\footnotetext{
*Correspondence: natalie.brown.14@ucl.ac.uk

${ }^{1}$ Institute for Sustainable Heritage, University College London, London, UK

Full list of author information is available at the end of the article
}

paper, or finishing. As a result, there is a significant lack of understanding of the material properties of historic Chinese paper within the generally accessible science and conservation literature. Yet, such information could significantly improve our understanding of the history of this craft and of the care of Chinese paper collections.

Conversely, the general practice of papermaking in China is well documented [1,5-8]. The raw materials varied regionally, and many plants were used for manual papermaking; including hemp, paper mulberry, cotton, ramie, rattan, flax, bamboo, jute, rice, wheat straw, and blue sandalwood. From the early 20th century on, both wood pulp and traditional fibres have been used for machine made papers. The papermaking process and stock preparation varied between mills, but impurities, like bark, were generally removed by hand while pulping was manual or semi-mechanical, using machines similar to Hollander beaters. Dispersion aids, often the root extract of Abelmoschus manihot (L.) Medik [9], and additives, such as kaolin, wood ash or lime [1] were added to the pulp mix prior to sheet formation. Surface sizing was not common. 
It is known that Chinese papermaking industry did not follow Western industrialisation in the 19th century, and did not rely on the same raw materials [10]. The time period of particular interest to this research is the 19th and 20th century, a period of change, where advancing technologies enabled a shift from handmade to mass produced machine paper. In addition, the period of interest includes the Cultural Revolution in China (1966-1967), where there was a strong promotion of industrialisation that introduced lasting changes to the papermaking industry [10]. This may have had an effect on the material stability, though no research is currently available.

Paper is a relatively stable organic material; however, its main structural component cellulose undergoes a series of degradation processes [11]. These depend on environmental conditions as well as on material composition [12]. Within this study, traditional destructive analysis was carried out to explore $\mathrm{pH}$, degree of polymerisation (DP), zero-span tensile strength and lignin content. Standardised characterisation methods were used such as cold extraction for $\mathrm{pH}$, viscometry to determine DP, and the phloroglucinol spot test for semi-quantitative determination of lignin content. A modified method for zero-span tensile testing was developed to allow for the typically low grammage of Chinese paper. Finally, 178 samples from the UCL Institute for Sustainable Heritage Historic Reference Material Collection were dated based on textual analysis.

While these results represent a systematic material study of the chemical and physical properties of a selection of modern Chinese papers, the destructive character of the chemical analytical methods precludes their use in collections of historic value. Many non-destructive techniques have been used in historic paper research: of the Fourier-Transform Infrared (FTIR) sampling techniques, attenuated total reflectance is often used, however, the requirement to apply pressure during a measurement makes it unsuitable for fragile objects. Raman spectroscopy can be very useful for ink and pigment analysis [13] or characterisation of lignin and cellulose degradation products [14]. However, the often low signal-to-noise ratio and fluorescence make it less suitable as a general characterisation technique. X-ray fluorescence spectroscopy (XRF) is widely used for elemental analysis; however, it is routinely used only for elements heavier than silica [15] and it does not provide any useful information on the organic components of paper.

Near-infrared spectroscopy (NIR) in conjunction with multivariate data analysis has been successfully applied to determination of properties such as $\mathrm{pH}$, degree of polymerisation (DP), lignin content, mechanical properties and age in European and Islamic papers [16-18] and quantitative imaging applications have been developed
[19]. NIR spectra contain fewer specific spectral features than mid-IR, as overtone and combination bands overlap, making band assignment challenging. However, using chemometrics, quantitative information can be extracted, resulting in a portable, non-destructive and reasonably affordable alternative to many other spectroscopic techniques. Due to the significant differences in the composition of European and Chinese paper, specific NIR methods may need to be developed in order to enable this type of spectroscopy to be used in systematic surveys of Chinese library and archival collections.

In this research, we explore the material properties of a large selection of modern Chinese paper to shed light on their composition, specifically in view of their stability and potential conservation issues. We use a reference collection for this purpose as destructive sampling was required. However, we also explored the potential for development of non-destructive NIR methods, which would allow us to explore historically significant collections in the future.

\section{Materials and methodology Samples}

The UCL Institute for Sustainable Heritage Historic Reference Material Collection of Chinese paper was used (Fig. 1). The samples were selected on the basis of age, size, method of production (handmade or machinemade), as well as diversity, such that they represented the evolving paper production industry within 19th and 20th century China. Within the sample set, 110 papers were visually assessed as handmade and 68 papers as machinemade. The dates are considered as approximate, particularly for samples obtained from antique shops, unless the samples themselves contained a date. In total, 178 papers, ranging from $\sim 1800$ to 1990 (Fig. 2), were used.

To reduce measurement uncertainty, samples were not taken from within a $1-\mathrm{cm}$ wide margin of a document. Similarly, areas containing ink, stains or mould were not used.

\section{$\mathrm{pH}$}

Acidity was measured following the TAPPI T 509 standard [20], with previously suggested modifications [21]: $1.0 \pm 0.1 \mathrm{mg}$ sample was extracted in $100 \mu \mathrm{l}$ of distilled water and soaked overnight. A Mettler Toledo SevenGo $\mathrm{pH} /$ Ion Meter (Columbus, $\mathrm{OH}$ ) with a micro-combined glass electrode was used. For calibration, Mettler Toledo pH $4.01 \pm 0.02$ and pH $9.21 \pm 0.02$ buffers were used at room temperature. The sample was removed from the solution prior to measurement. Values were rounded to the nearest $\pm 0.01 \mathrm{pH}$ unit. The typical measurement uncertainty was $1-11 \% .178$ papers were measured in triplicate and the measurements were averaged. 


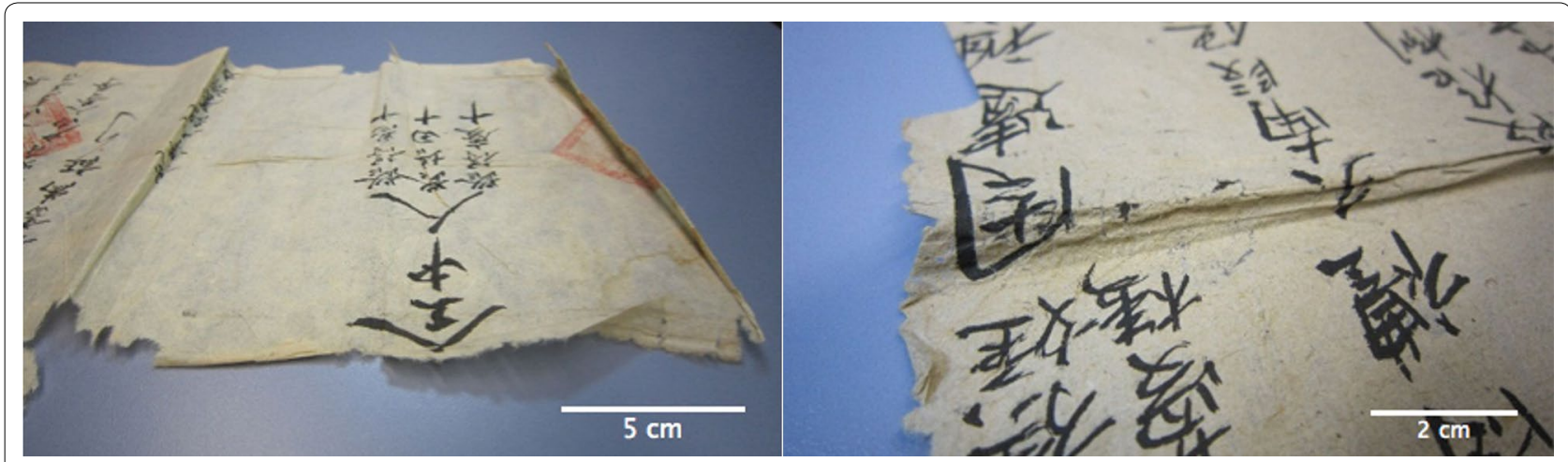

Fig. 1 Two typical samples of handmade paper from the reference collection

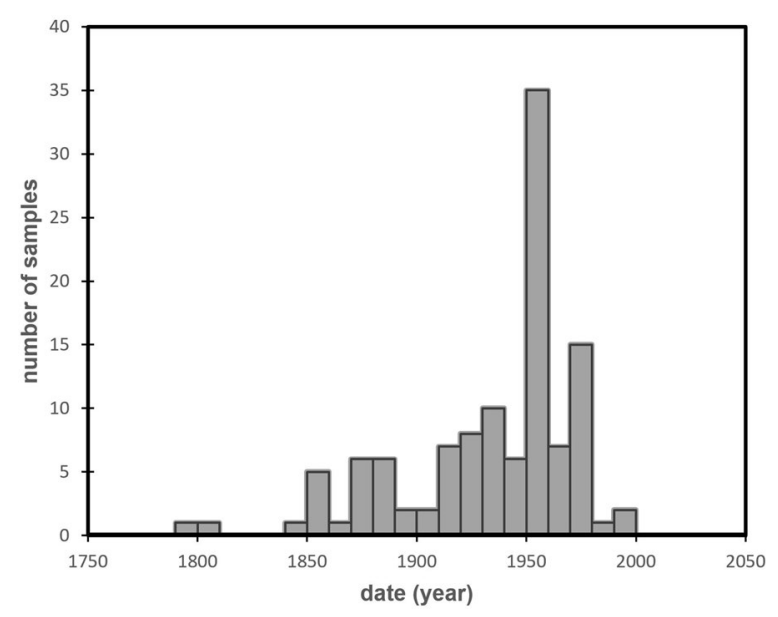

Fig. 2 Distribution of dates within the reference collection

\section{Degree of polymerisation}

The standard viscometric method was used (BS ISO 5351:2004 [22]). $20 \mathrm{mg}$ of paper was dissolved in $20 \mathrm{ml}$ of solution, consisting of $10 \mathrm{ml}$ cupriethylenediamine (CED) and $10 \mathrm{ml}$ deionised water. The efflux time of a solution was measured in triplicate at $25{ }^{\circ} \mathrm{C}$ to $0.01 \mathrm{~s}$ accuracy. Furthermore, triplicate samples of 20 papers were measured to determine the average measurement uncertainty, which was $10-15 \%$. For comparison, the measurement uncertainty for DP of Whatman No 1 filter paper (Maidenhead) was determined to be $1 \%$.

Subsequently, to save resources, two separate samples were tested from the rest of paper samples. If the variance between the two samples was greater than the previously observed maximum uncertainty (15\%), a third sample was measured and the average was calculated. 22 samples were thus additionally measured in triplicate. Out of these, the Dixons q-test at a $90 \%$ level of confidence was used to determine two individual outlier measurements.
The limiting viscosity number was determined using the Wetzel-Elliot-Martin's equation [23], with the moisture content assumed to be $5 \%$, as due to limited sample availability it was not possible to determine it accurately. Similarly, ash content could not be determined, however, since none of the papers contained fillers as contemporary Western papers do, this is not considered to be a major source of error. The Mark-Houwink-Sakurada equation was used to calculate DP [24].

The method is not suitable for lignin-containing papers due to lack of solubility. In 20 handmade papers, barklike tissue was removed from the sample. These impurities, rare and local, could affect the properties of paper locally, but not at the level of a paper sheet, and were not soluble in CED. DP was determined for 94 papers that tested negatively using the phloroglucinol test.

\section{Lignin content}

The presence of lignin was determined using the phloroglucinol spot test according to the standard procedure (TAPPI T 401 [25]). Colour change was assessed on a 3 -point scale. $0-$ no colour change, $1-<1 / 4$ of fibres exhibiting colour change, $2->1 / 4$ of fibres exhibiting colour change. 178 papers were tested.

\section{Thickness}

Three to five measurements were taken for each paper using a digital caliper $(0.001 \mathrm{~mm}$ readability). Dixons q-test, at a $90 \%$ level of confidence was performed to determine two outlier measurements. 178 papers were tested.

\section{Tensile strength properties}

Tensile strength was measured using the zero-span method (BS ISO 15361:2000 [26]), modified by using a Zwick Roell tensile strength instrument BT1-Fr0.5TS. D14 (Ulm, Germany) with custom-made zero span 
clamps. Several parameters were modified: the strip length was optimised to best fit the clamps without using excess material (Fig. 3), while the sample orientation followed previous research where zero-span was used to measure Western handmade papers [27]. Only 45 samples were available in a quantity large enough that 12 measurements could be performed $(84 \mathrm{~cm} \times 18 \mathrm{~cm})$.

Several strip lengths were tested: $60-100 \mathrm{~mm}$. $70-\mathrm{mm}$ strips were the shortest strips that could be repeatably positioned in the clamps. The $\mathrm{z}$ force $(\mathrm{N})$ and strain $(\mathrm{mm})$ of twelve $70 \times 15 \mathrm{~mm}$ strips were measured for each tested paper. The highest and lowest values were excluded from calculation of the average, which was corrected for paper grammage to calculate zero-span tensile strength index, following the standard.

\section{Spectroscopic analysis}

NIR measurements were performed using a Polychromix PHAZIR ${ }^{\mathrm{TM}}$-1624 Handheld NIR Analyzer (Wilmington, MA), equipped with a tungsten light source, and an InGaAs detector. Reflectance spectra were collected in the wavelength interval of $1600-2400 \mathrm{~nm}$, one sample point per document, with 9 averaged spectra, at 11-nm resolution. For single-sheet measurements, the sampling point was chosen such that it was near the sampling area for chemical and mechanical characterisation, while for 5 -sheet measurements this was not possible to ensure. All the measurements were performed at $20 \pm 2{ }^{\circ} \mathrm{C}$, $40-45 \% \mathrm{RH}$. The white calibration cap was used as a back reflector. 178 samples were measured.

\section{Multivariate data analysis}

Partial least squares (PLS) regression was performed using the Polychromix Model Generator software (Wilmington, MA) to develop applications for $\mathrm{pH}$, date, and $\mathrm{DP}$ determination. Samples were randomly allocated into calibration and validation sets. The calibration set comprised of $2 / 3$ of the observations, and independent full validation was performed using the remaining samples as a validation set. Due to the small number of samples, only calibration was carried out for zero-span tensile strength. Different spectral processing calculations were tested: a combination of either multiplicative scatter correction or standard normal variate, and first or second order Savitzky-Golay algorithm with a three or five-point window was used depending on the model (Table 2). The wavelength interval was kept at 1600-2400 nm. The number of factors was optimised using the validation set.

The root mean square error of prediction (RMSEP) for each model was calculated using

$$
\operatorname{RMSEP}=\sqrt{\frac{\sum_{i=1}^{n}\left(y_{i}-\hat{y}_{i}\right)^{2}}{n}},
$$

where $y_{i}$ is the measured and $\hat{y}_{i}$ is the predicted value.

Linear discriminant analysis (LDA) was performed using XLStat (Addinsoft, Paris) for lignin data classification, while the pre-processing of the spectral data was performed in Mathworks Matlab (Natick, MA). As above, samples were randomly allocated into training and validation sub-sets. Different spectral processing calculations were tested on both sub-sets in Matlab; first derivative with a window width of 5 , with either multiplicative scatter correction or standard normal variate. Principal component analysis (PCA) was then performed in Matlab to acquire the principal component scores [28]. The papers were classified according to their lignin content on the basis of their principal component scores in XLStat. As the measure of accuracy, the percentage of correctly classified samples (\% correct in Table 1) was used. Within-class covariance matrices were assumed to be equal, prior probabilities were not taken into account. Separate method validation was performed using the validation sub-set and the number of factors was optimised based on \% correctly classified samples.

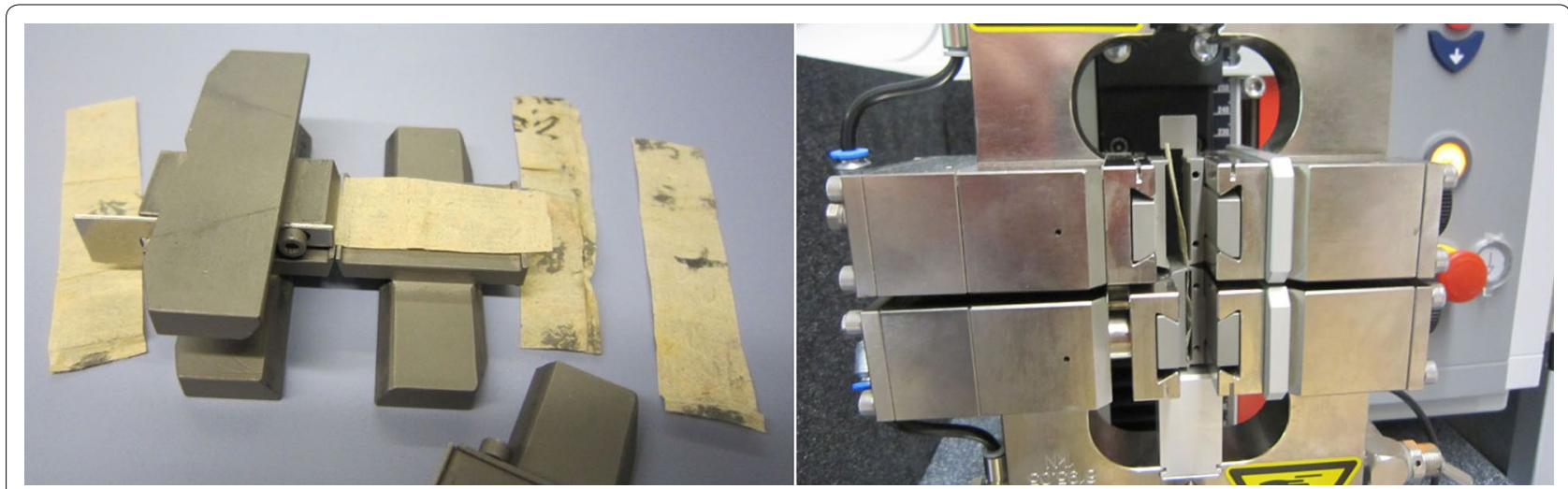

Fig. 3 The position of the modified clamps and paper used in zero-span measurements 
Table 1 Training, validation, and cross-validation matrices for the best performing LDA models for identification of lignin, using 5 sheets (above) and 1 sheet (below)

\begin{tabular}{|c|c|c|c|c|c|c|c|c|c|c|c|c|c|}
\hline \multirow[t]{2}{*}{ LDA model } & \multicolumn{5}{|c|}{ Training } & \multicolumn{4}{|c|}{ Validation } & \multicolumn{4}{|c|}{ Cross-validation } \\
\hline & $\begin{array}{l}\text { Low } \\
(0 / 1)\end{array}$ & $\begin{array}{l}\text { High } \\
(2)\end{array}$ & Total & $\%$ correct & Pre-processing & $\begin{array}{l}\text { Low } \\
(0 / 1)\end{array}$ & $\begin{array}{l}\text { High } \\
(2)\end{array}$ & Total & $\%$ correct & $\begin{array}{l}\text { Low } \\
(0 / 1)\end{array}$ & High (2) & Total & $\%$ correct \\
\hline $\operatorname{Low}(0 / 1)$ & 71 & 9 & 80 & 89 & \multirow{3}{*}{$\begin{array}{l}f(\mathrm{X}), \mathrm{SNV}, 4 \mathrm{PC} \\
\text { scores }\end{array}$} & 43 & 0 & 43 & 100 & 71 & 9 & 80 & 89 \\
\hline High (2) & 4 & 24 & 28 & 86 & & 3 & 8 & 11 & 73 & 4 & 24 & 28 & 86 \\
\hline Total & 75 & 33 & 108 & 88 & & 46 & 8 & 54 & 94 & 75 & 33 & 108 & 88 \\
\hline $\operatorname{Low}(0 / 1)$ & 72 & 8 & 80 & 90 & \multirow{3}{*}{$\begin{array}{l}f(x), M S C, 5 \text { PC } \\
\text { scores }\end{array}$} & 42 & 1 & 43 & 98 & 71 & 9 & 80 & 89 \\
\hline $\operatorname{High}(2)$ & 4 & 24 & 28 & 86 & & 1 & 10 & 11 & 91 & 5 & 23 & 28 & 82 \\
\hline Total & 76 & 32 & 108 & 89 & & 43 & 11 & 54 & 96 & 76 & 32 & 108 & 87 \\
\hline
\end{tabular}

When calculating first derivative $(f(x))$, the window width of 5 was used

\section{Results and discussion}

The distribution of the properties in the sample set validates many of the statements about material properties in the available secondary Chinese paper literature. Where available, paper thickness, $\mathrm{pH}, \mathrm{DP}$, lignin content and zero-span tensile strength were plotted against paper production date (Figs. 4, 5). The $\mathrm{pH}$ values are generally $>6$ well into the 20th century, which confirms the known absence of use of acidic sizing, as well as low lignin content in both handmade and machine-made papers [29]. The pattern of DP tends towards higher values with age, which indicates a gradual change in fibre pre-treatment or raw material with time, with lower quality fibres having been used in later periods. Machine made papers were observed mainly after 1950, when chemical removal of lignin became regular practice in industrial papermaking [30,31], but it is known that wood pulp was also imported to China from mid-20th century on [31]. Papers with high lignin content were not present in the sample set until 1946, and all were machine made. There is an equal distribution of low lignin content papers throughout the period as papermaking by hand was popular until
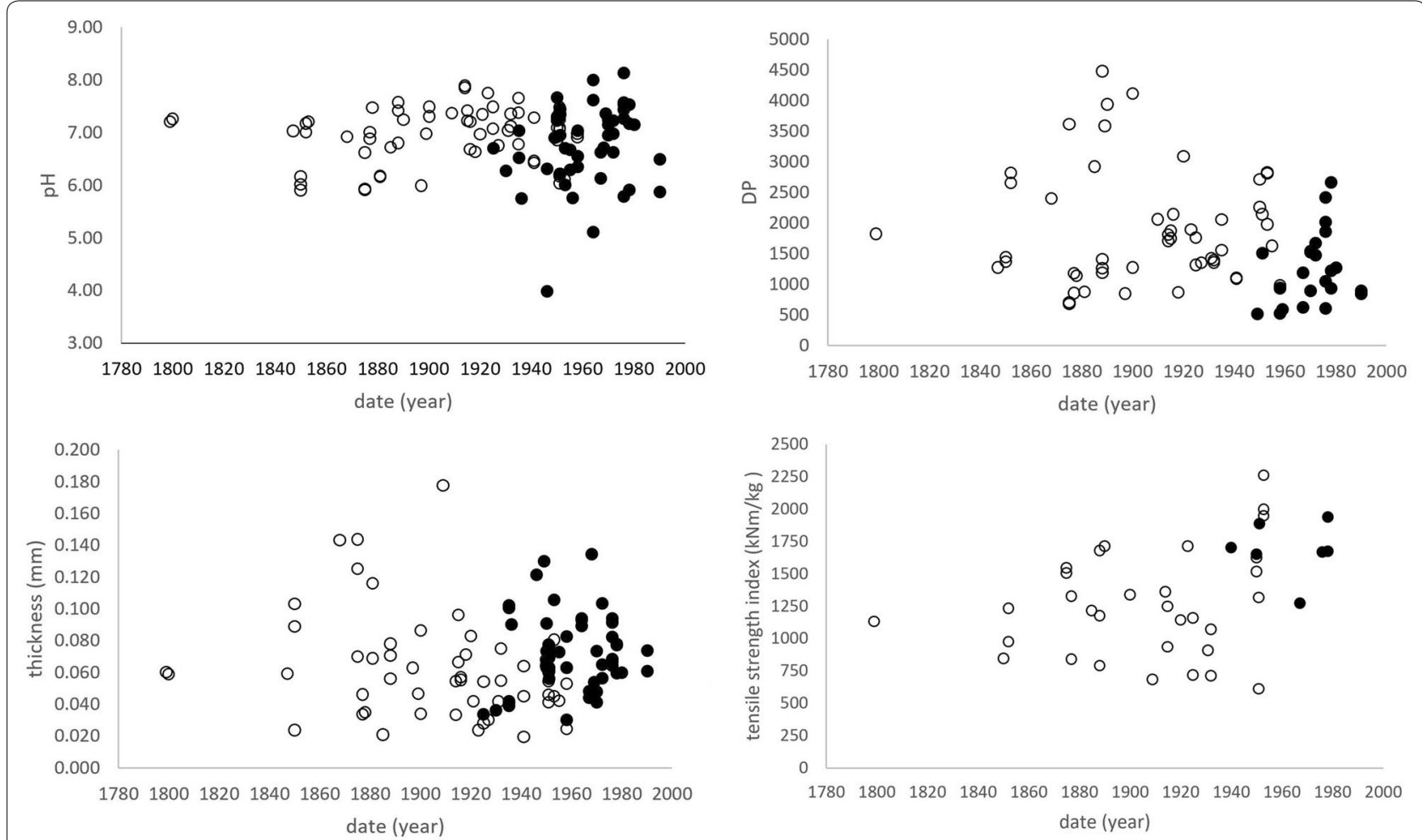

Fig. 4 pH, DP, thickness, zero-span tensile strength vs. date. Black circles indicate machine made papers and white circles indicate handmade papers 


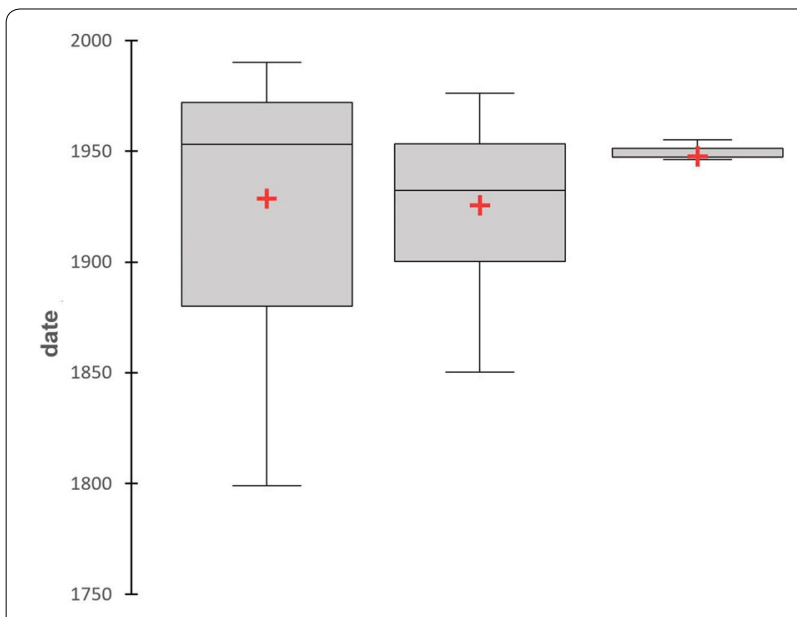

Fig. 5 Boxplots of date vs. lignin content. ' $O$ ' on the left, ' 1 ' in the middle, '2' on the right

mid-1960s and early machine-made papers were often made using fibres of naturally low lignin content, as well as chemically delignified fibres (Fig. 5).

The measurements of zero-span tensile strength show a gradual decrease with age, which is in an interesting contrast with DP measurements. This indicates that tensile properties differently depend on intra- and inter-fibre bonding in handmade and machine-made papers.

Another specific property of the characterised collection of Chinese paper samples is low grammage. Figure 6 shows that handmade papers are biased towards lower thicknesses. The observed variability in thickness is higher than that for Western papers from the same period: 19th century handmade European papers have a thickness between 0.07 and $0.14 \mathrm{~mm}$ [27], whereas handmade papers from the sample set have a thickness between 0.01 and $0.17 \mathrm{~mm}$. 20th century Western machine-made papers have a thickness between 0.08 and $0.18 \mathrm{~mm}$ [1], whereas machine-made papers from the sample set measured 0.03 and $0.014 \mathrm{~mm}$. For determination of thickness, handmade papers exhibited higher RSD (3-83\%) than machine-made papers (1-9\%) for individual samples, which demonstrates higher dimensional homogeneity in industrial machine-made papers.

It is important to note that handmade Chinese papers are also compositionally inhomogeneous, which was evident from the high analytical uncertainties as observed for a number of measured properties. Paper thickness and homogeneity are important for this research as they affect the repeatability of spectra and thus reliability of multivariate data analysis, and may also affect the local stability of paper.

\section{Chemical properties \\ pH}

Paper acidity/alkalinity is a crucial parameter regulating the mechanisms and defining the rates of degradation of cellulose [12]. Overall, the $\mathrm{pH}$ of the reference collection averaged at 7.6 (Fig. 7), with only a few handmade samples having $\mathrm{pH}<6$. The usual causes of acidity within paper are well-known: alum/rosin sizing, lignin (causing acidity due to oxidation), residual chemicals from papermaking processes, and air pollutants [21].
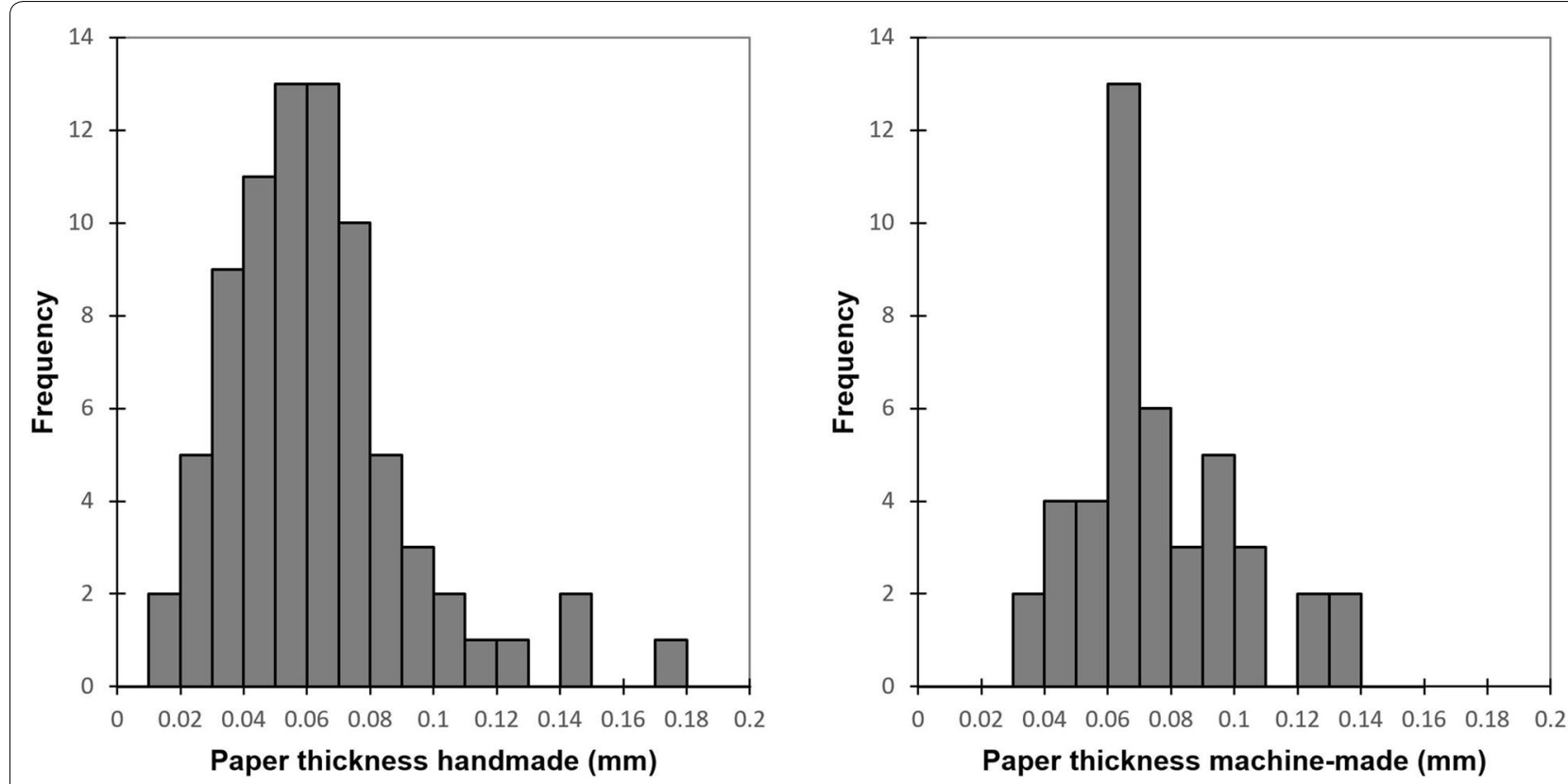

Fig. 6 Thickness distributions for handmade (left) and machine-made papers (right) in the reference collection 

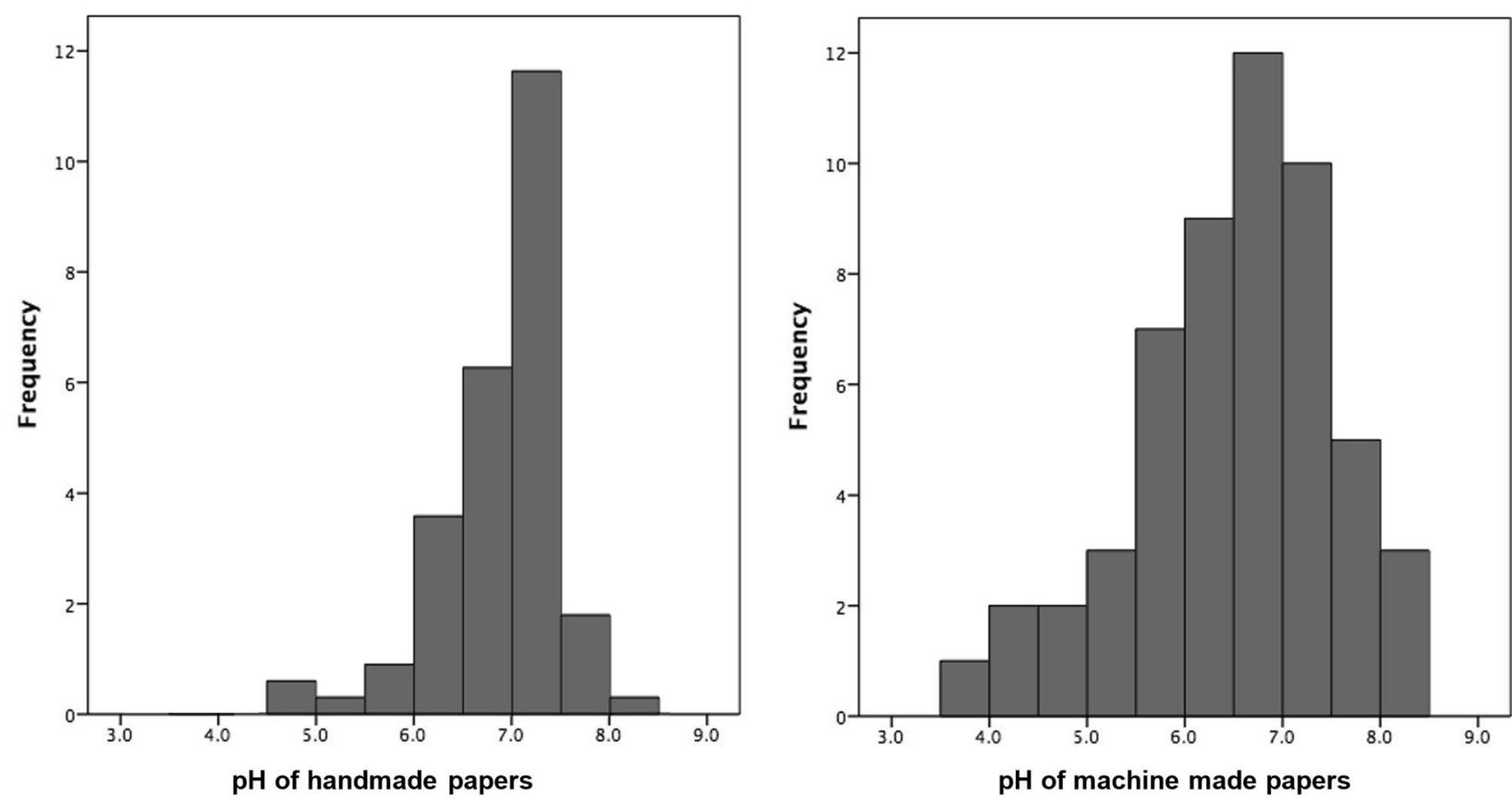

Fig. 7 Distribution of pH of handmade (left) and machine-made papers (right) in the reference collection

There is little evidence within the papermaking literature of alum sizing or additives being used in 19th and 20th century Chinese papermaking. Dispersion aid derived from the mucus of Abelmoschus manihot (L.) Medik was commonly used [9], but this does not appear to influence $\mathrm{pH}[32,33]$. During the 19th and 20th centuries, handmade papers made from 'traditional' paper mulberry, bamboo, and bast fibres such as flax, were widely used in mass production. These fibres have a relatively low lignin content, compared to wood pulp used in Europe [29]. Traditionally, chemical bleaching was not used for handmade papers in China; instead, sun bleaching during drying was common [1]. The distribution of $\mathrm{pH}$ thus does not follow that of 19th and early 20th century Western paper, where $70-80 \%$ of paper produced between 1850 and 1990 are acidic [16, 34].

There are only a few papers with $\mathrm{pH}<5$ in the sample set. It is known that as the papermaking process became more industrialised during the mid-20th century, Western practices started to permeate the industry [10,30] which could contribute to the lower $\mathrm{pH}$ values. Canadian wood pulp, mixed with traditional fibres was introduced mid-20th century to some Chinese production mills. Chemical bleaching and lignin removal was also introduced during this time [31] and it is also possible that Western acidic paper was imported to China.

Handmade papers exhibited a significant variance in $\mathrm{pH}$ measurements, which is ascribed to inhomogeneous fibre distribution and localised compositional differences.
The RSD for measurements of the same sample was up to $20 \%$ ( $0.8 \mathrm{pH}$ units), which is high in comparison with Western paper, where values of 0.3 are typically observed [21]. The observed high variance could lead to significant differences in degradation locally. As well as this, high RSD may affect the quality of the PLS model, as we will explore later.

\section{Lignin content}

Due to oxidation, lignin leads to low colour stability of paper [35]. The amount of lignin in paper depends on the raw material and the paper making process [36]. Using the phloroglucinol test, colour change was visually observed in 105 samples, whereas 73 papers did not exhibit any noticeable colour change (Fig. 8).

Many handmade papers exhibited colour change restricted to individual fibres, indicating mixtures of lignin-free and ligneous fibres. In some handmade papers, clusters of lignin-containing fibres were found, which could result in localised degradation and yellowing in the future. Homogeneous colour change was observed in 15 papers, indicating that such paper was likely made wholly from bamboo or wood-derived pulp.

\section{Degree of polymerisation}

DP influences mechanical properties [37] and is thus an important measure of its fitness for use. It is also an important variable in the damage function for historic paper [12, 38, 39]. 


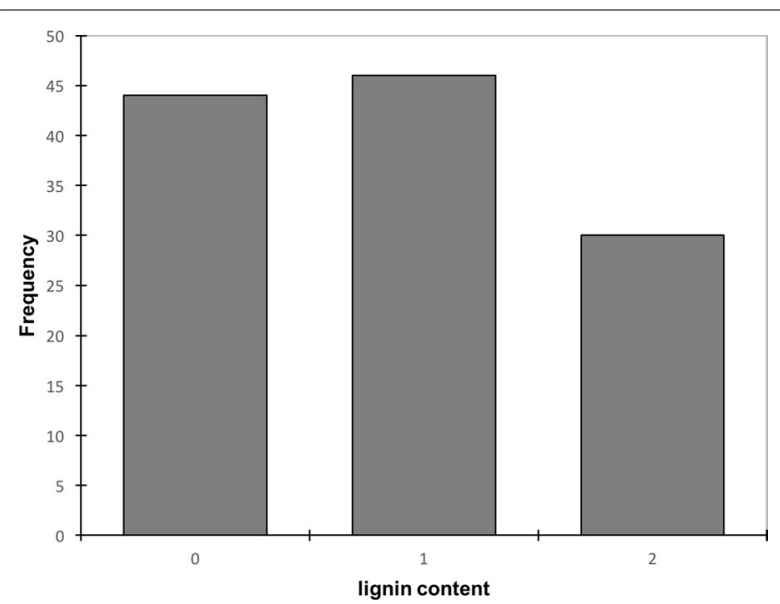

Fig. 8 Distribution of lignin content of both handmade and machine made papers in the reference collection

As papers with a high lignin content cannot be dissolved in cupriethylenediamine, a number of samples (83) from the reference collection could not be measured. Prior to DP determination, localised fibre clusters and other impurities (e.g. remains of bark) were removed from some samples in order to improve dissolution. However, this could have affected the measured DP values as well as multivariate data analysis.

The mean DP values for handmade and machine-made papers are 1860 and 1240 respectively (Fig. 9). These values resemble the DP of pre-1850 European rag paper, which ranges between 810 and 3800 [37, 40]. Few traditional papermaking techniques reported in East Asia utilised oxidising, highly alkaline or highly acidic chemicals, with the exception of the use of caustic soda [32,33], which could result in $\mathrm{pH}$ values above 9, which was not observed in our study (Fig. 7). Due to the lack of solubility, less DP data is available for machine-made papers, although this compares favourably with that of 20th century European machine-made papers, which ranges between 200 and 1500 [37, 41].

In relation to the method, the observed inhomogeneous fibre distribution and localised impurities in handmade papers created significant variance of $>200$ DP, i.e. $>15 \%$ RSD was observed for triplicate measurements of the same sample, in 20 samples. The high RSD may affect the reliability of multivariate data analysis, as we will explore later.

\section{Mechanical properties}

\section{Zero-span tensile strength}

Preliminary tearing tests have shown that handmade Chinese papers have low inter-fibre bonding but high fibre strength. As the zero-span test is a widely accepted method of measurement of fibre strength within a sheet [42], it was the method of choice, although the role of inter-fibre bonding in this property is still not fully understood [43]. Another criterion for this choice was that smaller samples are needed, compared to tensile strength testing.

In previous research on Western rag paper [27], it was concluded that measuring parallel to chain lines yielded higher values in the majority of papers due to the grain direction created by the action of the mould going into the vat during sheet formation. Our own measurements confirmed this, however, there was a higher variance between measurements. It was observed that in many papers there was an increased concentration of fibres along chain lines, which led to higher variance. It was therefore decided to measure parallel to laid lines, $5 \mathrm{~mm}$ from the nearest chain line, to exclude areas with inhomogeneous pulp deposits. The results are reported in tensile index $(\mathrm{kNm} / \mathrm{kg})$ a measure of inherent strength in the paper (Fig. 10). As a methodology has been developed in this research project, there is no directly comparable data available; however, contemporary softwood kraft paper has been found to have a lower tensile index between 90 and $120 \mathrm{kNm} / \mathrm{kg}$ [44]. Machine-made papers were found to have a higher zero span tensile index on average. This could be the result of additives or sizing, e.g. the addition of starch into the pulp is known to yield higher values for paper made from softwood fibres [45]. There was no correlation between thickness and zero-span tensile strength $\left(R^{2}=0.004\right)$. Previous research established a correlation between DP and mechanical properties of paper [46]; however, our results do not confirm this for zero-span tensile strength of Chinese paper $\left(R^{2}=0.08\right)$.

\section{Near infrared spectroscopy}

While NIR methods have successfully been developed for characterisation of 19th and 20th century European paper $[16,17]$, the results discussed above show that the significantly different properties of Chinese paper might require specific methods to be developed. Due to the low grammage of Chinese paper, a study of the required number of layers of paper was carried out first to obtain a spectrum without the influence of the Additional file 1 as was done for European paper [16].

The spectra of 1-10 layers of paper were measured for 4 paper samples of different thicknesses (sample nos. $48 \mathrm{~B}, 54,33 \mathrm{~B}, 76)$. The spectra of $1-9$ paper layers were compared with the spectrum obtained for 10 layers of the same paper, by correlating absorbance values pairwise per wavelength (Fig. 11). The data demonstrates that at $\sim 5$ layers the values $R^{2}$ tend to level-off at $>0.99$, while the slopes are mostly $>0.8$. Thus, 5 layers of paper were explored as a suitable number of layers enabling successful multivariate data analysis. However, since in practice 

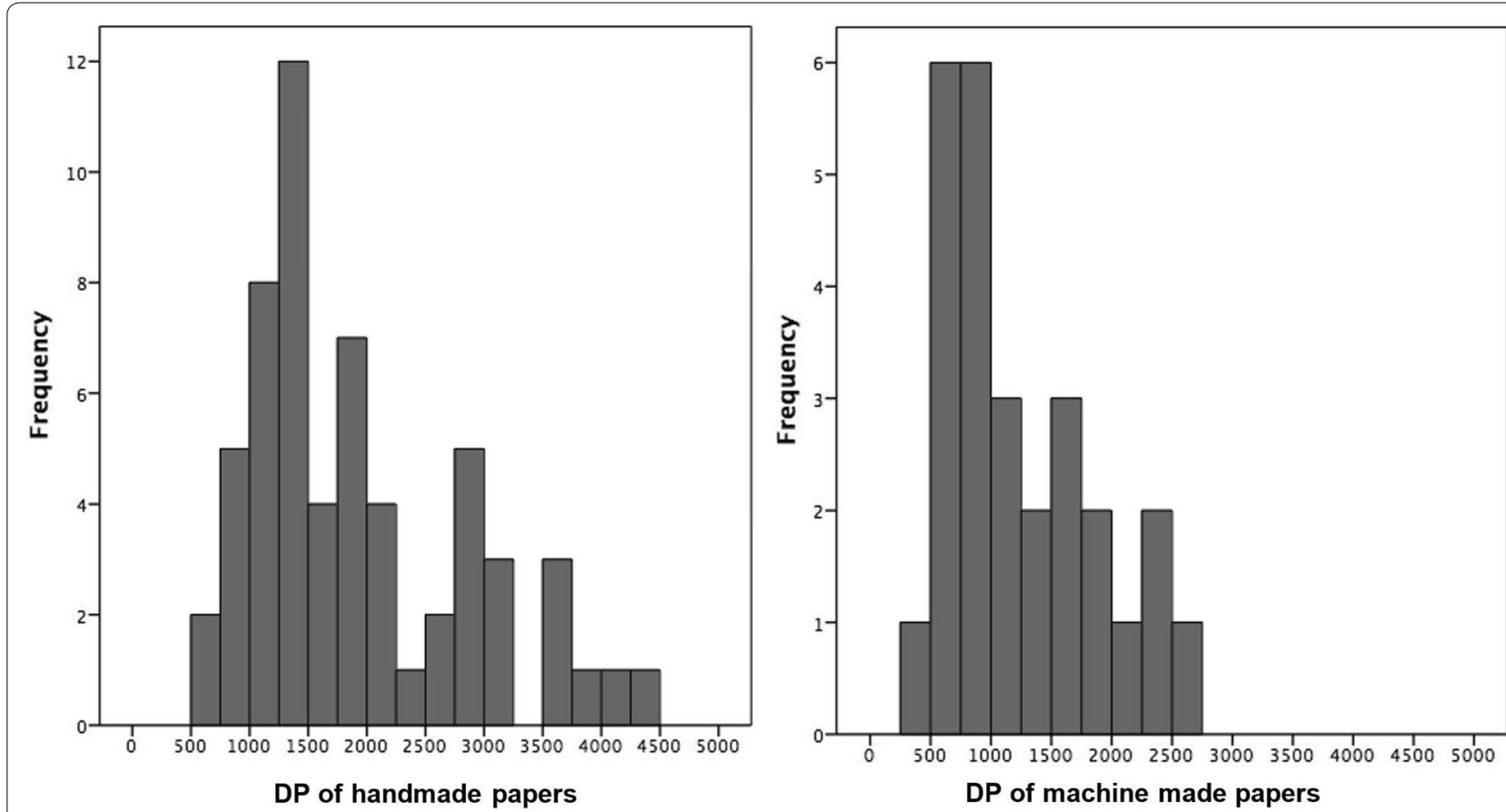

Fig. 9 Distribution of DP for machine-made (left) and handmade paper samples (right)

it might be difficult to fold an archival document into 5 layers, spectra using 1 layer were also measured and used for data analysis. From further analysis, 3 samples were removed as there was not enough material to perform 5-layer measurements, and a total of 173 samples were thus included in multivariate data analysis.

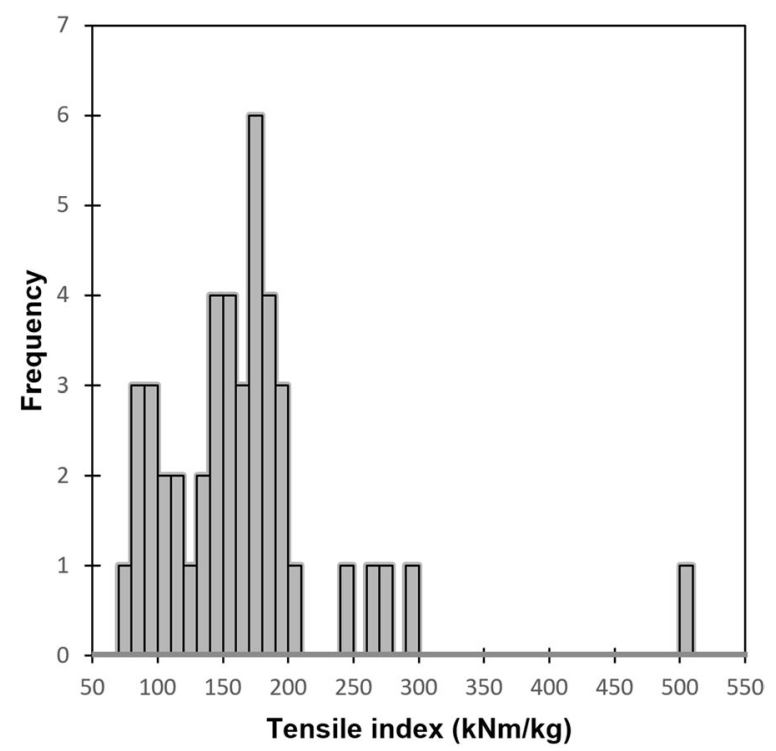

Fig. 10 Distribution of zero-span tensile strength for the measured samples from the Chinese reference paper collection $(N=45)$
Prior to multivariate data analysis, PCA was performed on the spectra to determine any outliers. 2 samples were found to have significantly different spectra from the rest. Visual assessment showed that the samples contained pink and brown dyes. As these samples represented exceptions and as the focus of this research is not to assess the properties of coloured papers, the samples were removed from further analysis.

For lignin content, LDA was used (Table 1) as quantitative data was not available. As the purpose of this research was to establish that in principle, lignin could be quantitatively determined using NIR spectroscopy, samples with individual fibre colour change (1) or no observable colour change $(\mathbf{0})$ following the phloroglucinol test were grouped together.

These results show that LDA models could be created to successfully distinguish between papers with a high content of lignin (2) and little or no lignin content $(\mathbf{0} / \mathbf{1})$. 18 out of the 41 samples with high lignin content came from 2 volumes consisting of 2 series of 7 and 11 books, which could have similar chemical properties although they visually appear different.

There are small, but statistically insignificant differences between the models. The spectra of a single layer were taken immediately beside the point where samples were taken for lignin determination, and the spectra taken across 5 layers represent averages across 5 sheets. There is no evidence of material inhomogeneity affecting the results of classification. 

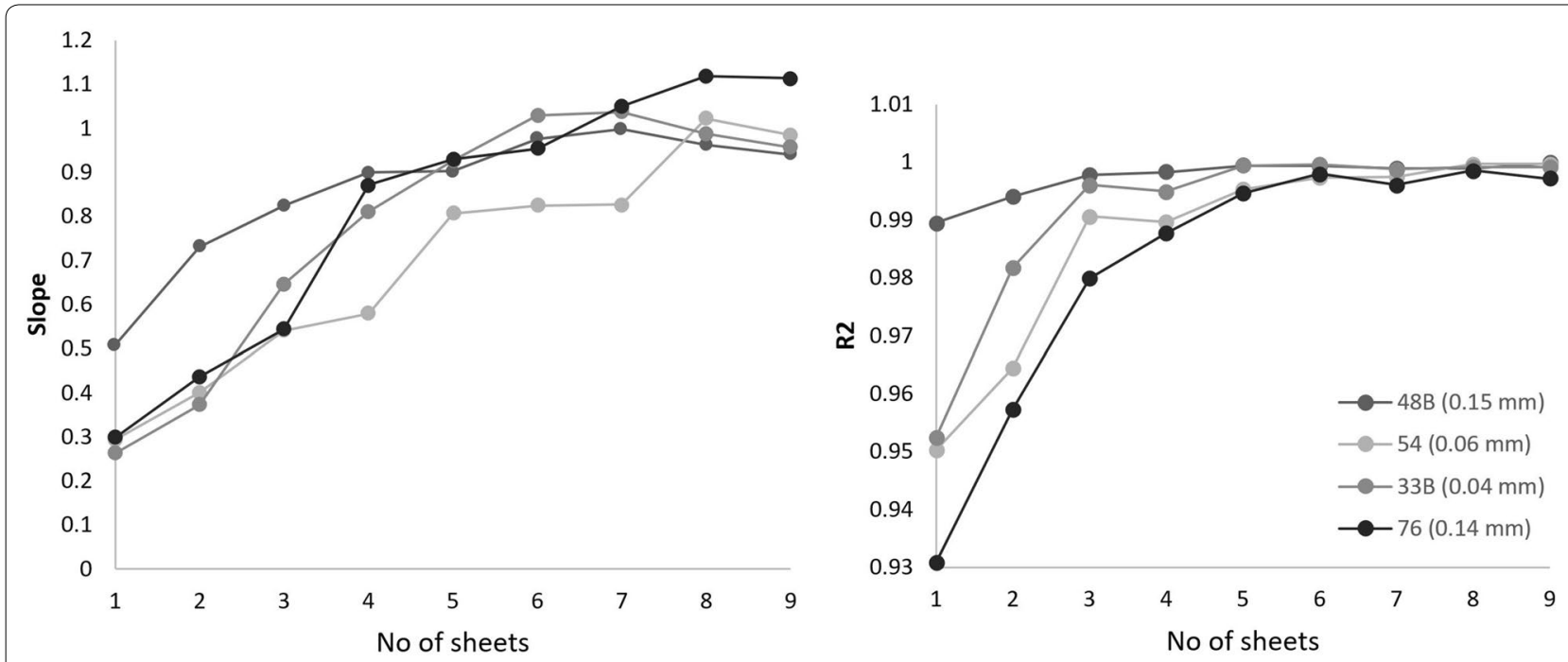

Fig. 11 Slopes (left) and correlation coefficients (right) for linear correlations obtained for absorbance values for 1-9 paper layers compared per wavelength with the values obtained for 10 layers of the same paper

Multivariate regression models were explored for nondestructive determination of date, tensile strength, $\mathrm{pH}$ and DP (Table 2).

In Fig. 12, PLS calibration and validation scatter plots are shown. Being able to date paper is important for scientific, conservation and curatorial reasons: the change in paper production technology in China that led to industrial standardisation could be more accurately followed, while from a conservation point of view, the age of a paper in conjunction with its $\mathrm{pH}$ and DP could reveal its stability. It is possible to hypothesise that dating of paper using NIR is enabled due to the accumulation of degradation products during ageing, as well as due to the frequent changes in the manufacturing processes of historic materials. Both are reflected in the NIR spectra and these in turn enable dating, as has been shown previously for paper as well as for photographs and parchment [47-49]. It is not possible, due to the highly overlapped NIR absorption peaks, to examine which compounds or bond types specifically contribute to the success of PLS regressions for dating.

The success of dating applications ultimately depends on the accuracy of historic data. These were extracted from the documents themselves where available, but are

Table 2 PLS calibration and validation parameters for regression models for date, pH, DP and zero-span tensile strength index (TSI); $N$-number of samples

\begin{tabular}{|c|c|c|c|c|c|c|c|c|c|}
\hline \multirow[t]{2}{*}{ PLS model } & & \multicolumn{5}{|c|}{ Calibration } & \multicolumn{3}{|c|}{ Validation } \\
\hline & & $N$ & RMSECV & Factors & $R^{2}$ & Pre-processing & $N$ & RMSEP & $R^{2}$ \\
\hline \multirow{5}{*}{ Five sheets } & Date & 112 & 21 & 6 & 0.6 & SNV, MSC & 33 & 24 & 0.53 \\
\hline & Date post-1900 & 86 & 9 & 9 & 0.67 & SNV, MSC & 29 & 15 & 0.47 \\
\hline & $\mathrm{pH}$ & 135 & 0.5 & 8 & 0.66 & MSC, S-Golay*, SNV & 38 & 0.7 & 0.37 \\
\hline & $\mathrm{DP}$ & 63 & 370 & 8 & 0.84 & SNV, MSC, S-Golay** & 21 & 690 & 0.52 \\
\hline & TSI & 45 & 28 & 8 & 0.69 & MSC, SNV, S-Golay* & - & - & - \\
\hline \multirow[t]{5}{*}{ One sheet } & Date & 112 & 21 & 7 & 0.64 & MSC, S-Golay*, SNV & 33 & 31 & 0.3 \\
\hline & Date post-1900 & 86 & 10 & 8 & 0.74 & SNV, MSC, S-Golay* & 29 & 13 & 0.41 \\
\hline & $\mathrm{pH}$ & 135 & 0.5 & 7 & 0.63 & MSC, S-Golay*, SNV & 38 & 0.7 & 0.4 \\
\hline & DP & 63 & 500 & 7 & 0.72 & SNV, MSC, S-Golay* & 21 & 720 & 0.55 \\
\hline & TSI & 45 & 30 & 8 & 0.63 & MSC, SNV, S-Golay* & - & - & - \\
\hline
\end{tabular}

Due to the low number of observations, independent validation was not carried out for TSI

*First derivative, three-point smoothing, second order polynomial

**Second derivative, three-point smoothing, second order polynomial 

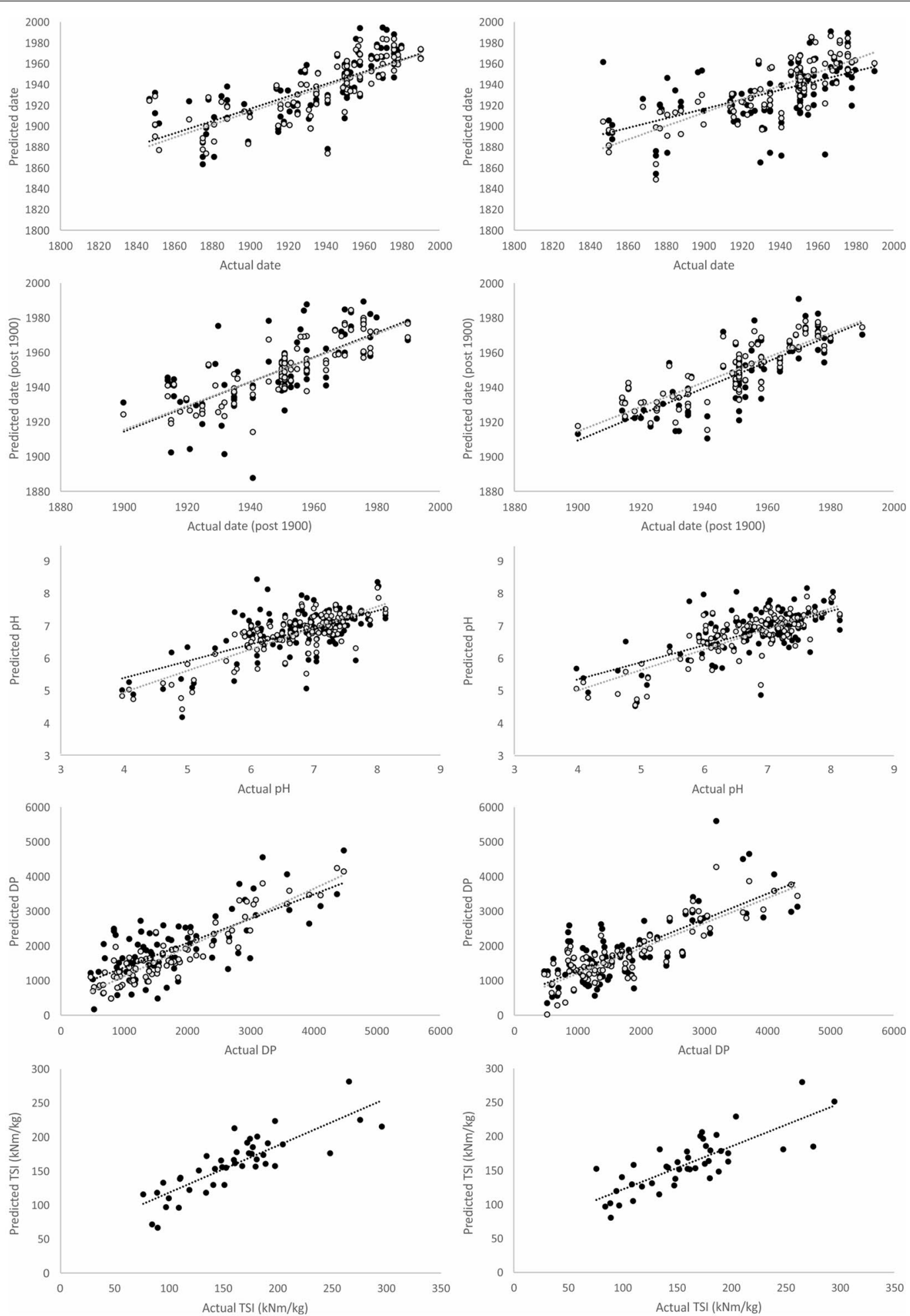

Fig. 12 Predicted vs. actual values for PLS calibrations and validations using 5 (left) and 1 (right) layers of paper. Black circles indicate calibration results and hollowed circles indicate validation results. The calibration (dark dotted line) and validation (light dotted line) data were fitted using linear regression 
of doubtful quality where supplier data was used instead, which was mostly the case of pre-1900 samples. For PLS, calibration was generally more satisfactory using 5 layers of paper, which probably reflects the amount of information that is reflected from a thick sample (5 layers) as compared to a thin one (single layer). The models can predict the date of paper with 21 years uncertainty; however, this is significantly reduced to 13 years for post-1900 samples. These values are very similar to those reported for European paper [16] which indicates that NIR spectroscopy, in conjunction with PLS, is a method that should be explored further for scientific characterisation of Chinese paper. Spectra of single sheets, while leading to less satisfactory calibrations, can for some properties be considered as acceptable if 5 sheets are not available.

However, the results for $\mathrm{pH}$ and DP are less satisfactory, in both cases the high RMSEP values indicate that the value of the current best calibrations to preservation is limited. There could be several reasons for this, to be explored further in future research: despite the number of samples used in this research, there is only a limited $\mathrm{pH}$ range covered (4.0-8.1) in the first place, with the vast majority in the range 6-7.5. Currently, the model is thus able to differentiate between acidic and alkaline samples; however, to increase the accuracy of the calibration, additional acidic paper samples would be needed. Similarly, for DP it also was not possible to obtain a reasonable quality of calibration, which could be due to the high variance of the DP determinations obtained viscometrically as a result of sample inhomogeneity. In this case it may not be possible to improve the calibration by increasing the number of samples, unless a different method for DP determination is used, requiring smaller samples, e.g. size exclusion chromatography.

A NIR model to evaluate the tensile properties would be valuable for preservation in collections that allow handling of the objects, as the strength of thin Chinese papers is difficult to gauge by handling. However, due to the small number of samples that were available for mechanical testing, we only present the calibration plot in Fig. 12, which shows that with a higher number of samples, an application could be developed in the future.

\section{Conclusions}

Systematic characterisation of 178 Chinese papers from 19th and 20th century was carried out using various known chemical, mechanical and spectroscopic techniques. The examined sample set was randomly collected and could thus be considered as a representative selection. Compared to Western paper from the same period, significant differences in the examined properties were observed. Although the storage history of the samples is unknown, the following conclusions can be drawn:
- Chinese papers are largely neutral with $\mathrm{pH}$ mostly between 6 and 8 , with only a small proportion of samples with $\mathrm{pH}<6$ (10\%).

- Lignin content varies, with $23 \%$ of samples showing a significant reaction using the phloroglucinol test. Only 15 samples showed intensive overall colouration.

- The average DP of the sample set was 1860 for handmade and 1240 for machine-made samples. These values are comparable with European papers of similar age.

- Low grammage of traditional Chinese papers is wellknown, and machine-made papers were on average $0.08 \mathrm{~mm}$ thick and handmade $0.06 \mathrm{~mm}$.

- A method for determination of zero-span tensile strength was developed and 45 samples could be measured, where enough material was available.

- A further characteristic property of traditional Chinese papers is inhomogeneity, which led to up to $20 \%$ variance between DP measurements, and up to $0.09 \mathrm{~mm}$ difference in sheet thickness within the same sample. The low grammage also affected NIR spectroscopic analyses: spectra of 1-10 layers of paper were compared and from 5 layers on, additional amount of material (i.e. more layers) was considered to no longer significantly affect the spectra.

- PLS regression and LDA models were developed for 1 and 5 layers of paper, for $\mathrm{pH}$, DP, zero span tensile strength index, age, and lignin content with varying success. While the model for dating was satisfactory, the $\mathrm{pH}$ model was least satisfactory due to the small range of $\mathrm{pH}$ values of samples in the collection. Models developed using spectra obtained with a single layer were comparable to those obtained with 5 layers, which is ascribed to material inhomogeneity.

Further research is required to optimise the developed NIR methods for practical application, as increased sample diversity would be desirable, particularly for $\mathrm{pH}$. Due to the observed differences with well-studied European paper, a quantitative understanding of degradation of traditional Chinese paper needs to be developed, which is the focus of our future research.

\section{Additional file}

Additional file 1. Sample table outlining the function of the sample, whether the sample is assessed to be handmade or machine made, date (when known), and the region of use/source of the sample.

\section{Authors' contributions}

$\mathrm{NB}, \mathrm{DL}, \mathrm{TF}$ and $\mathrm{MS}$ jointly developed the concept of this work. NB and DL carried out material analyses and all co-authors contributed to interpretation. All co-authors contributed to the manuscript. All authors read and approved the final manuscript. 


\section{Author details}

${ }^{1}$ Institute for Sustainable Heritage, University College London, London, UK.

${ }^{2}$ Lichtblau e.K., Dresden, Germany. ${ }^{3}$ Department of Statistical Science, University College London, London, UK.

\section{Acknowledgements}

The authors gratefully acknowledge the financial support of the EPSRC Centre for Doctoral Training in Science and Engineering in Arts, Heritage and Archaeology (SEAHA), as well as of Lichtblau e.K. Particular thanks go to Jan Wouters and Yun Liu for their help with this research and for useful advice.

\section{Competing interests}

The authors declare that they have no competing interests.

\section{Availability of data and materials}

The raw data that can be freely shared has been made available as Additiona file 1. The UCL Institute for Sustainable Heritage Reference Collection of Chinese Paper is available for scientific research at the institution.

\section{Consent for publication}

Written informed consent for publication was obtained for the manuscript from all contributors. The details and images in the manuscript will be freely available on the internet and may be seen but the general public.

\section{Ethics approval and consent to participate} Not applicable.

\section{Funding}

UK Engineering and Physical Sciences Research Council grant Centre for Doctoral Training Science and Engineering in Art, Heritage and Archaeology (EP/L016036/1).

\section{Publisher's Note}

Springer Nature remains neutral with regard to jurisdictional claims in published maps and institutional affiliations.

Received: 10 February 2017 Accepted: 9 October 2017

Published online: 24 November 2017

\section{References}

1. Hunter D. Papermaking: the history and technique of an ancient craft. New York: Dover Publications; 1947.

2. Collings T, Milner D. A new chronology of papermaking technology. Paper Conserv. 1990;14:58-62.

3. Hughes S. Washi: the world of Japanese Paper. New York: Kondansha America; 1978.

4. Barrett T. Japanese Papermaking: traditions, tools and techniques. New York and Tokyo: Weatherhill; 1983.

5. Needham J. Science and civilization in China. Cambridge: Cambridge University Press; 1954

6. Tsuen-Hsuin T. Raw materials for old Papermaking in China. J Am Orient Soc. 1973;93:510-9.

7. Collings T, Milner D. Identification of oriental paper-making fibres. Paper Conservator. 1978;3:51-79.

8. Rumford J. Out of the moving waves - some notes on Chinese Papermaking. Handmade Papermak. 1989;4:6-9.

9. Yum H. History and function of dispersion aids used in traditional East Asian Papermaking. J Inst Conserv. 2011;34:202-8.

10. Eyferth J. De-industrialization in the Chinese Countryside: handicrafts and development in Jiajiang (Sichuan), 1935 to 1978. China Quart. 2003;173:53-73.

11. Strlič M, Kolar J. Ageing and stabilization of Paper. Ljubljana: National and University Library; 2005

12. Strlič M, Grossi-Sampedro C, Dillon C, Bell N, Fouseki K, Brimblecombe P, Menart E, Ntanos K, Lindsay W, Thickett D, France F, De Bruin G. Damage function for historic Paper. Part III: isochrones and demography of collections. Herit Sci. 2015;3:40.
13. Piantanida G, Menart E, Bicchieri M, Strlič M. Classification of iron-based inks by means of micro-Raman spectroscopy and multivariate data analysis. J Raman Spectrosc. 2013;44:1299-305.

14. Strlič M, Šelih VS, Kolar J, Kočar D, Pihlar B, Ostrowski R, Marczak J, Strzelec M, Marincek M, Vuorinen T, Johansson LS. Optimisation and on-line acoustic monitoring of laser cleaning of paper. Appl Phys A. 2005:81:943-51.

15. Stuart B. Analytical techniques in materials conservation Chapter 4 Chichester: John Wiley \& Sons; 2007.

16. Trafela T, Strlič M, Kolar J, Lichtblau DA, Anders M, Pucko Mencigar D, Pihlar B. Non-destructive analysis and dating of historical paper based on IR spectroscopy and chemometric data evaluation. Anal Chem. 2007;79:6319-23.

17. Lichtblau DA, Strlič M, Trafela T, Kolar J, Anders M. Determination of mechanical properties of historical paper based on NIR spectroscopy and chemometrics - a new instrument. Appl Phys A. 2008:92:191-5.

18. Mahgoub H, Bardon T, Lichtblau D, Fearn T, Strlič M. Material properties of Islamic Paper. Herit Sci. 2016:4:34.

19. Cséfalvayová L, Strlič M, Karjalainen H. Quantitative NIR chemical imaging in heritage science. Anal Chem. 2011:83:5101-6.

20. TAPPI 509 om-88 Hydrogen ion concentration $(\mathrm{pH})$ of paper extracts (cold extraction method); 1988

21. Strlič M, Kolar J, Kočar D, Drnovsek T, Šelih VS, Susič R, Pihlar B. What is the pH of alkaline paper? e-Preservation. Science. 2004;1:35-47.

22. BS ISO 5351:2004 Pulps_-determination of limiting viscosity number in cupri-ethylenediamine (CED) solution; 2004.

23. Martin AF. Toward a referee viscosity method for cellulose. TAPPI. 1951;34:363-6.

24. Evans R, Wallis A. Cellulose molecular weights determined by viscometry. J Appl Polym Sci. 1989;37:2331-40

25. TAPPI 401 om-15 Fiber Analysis of paper and paperboard; 2015

26. BS ISO 15361:2000 Pulps-determination of zero-span tensile strength, wet or dry; 2000

27. Barrett T, Ormsby M, Shannon R, Brukle I, Lang, J, Schilling M, Mazurek J, Wade J, White J. Experiments A and B: Non-destructive analysis during treatment. Paper through time: nondestructive analysis of 14th-through 19th-century papers. The University of lowa. http://paper.lib.uiowa.edu/ experiments.php. Accessed 20 Jan 2017.

28. Miller JN, Miller JC. Statistics and chemometrics for analytical chemistry. 6th ed. Upper Saddle River: Prentice Hall/Pearson; 2010.

29. Marques G, Rencoret J, Gutiérrez A, del Río J. Evaluation of the chemical composition of different non-woody plant fibers used for pulp and paper manufacturing. Open Agric J. 2010;4:93-101.

30. Seki M. Database of traditional papermaking centres in East Asian Regions. Res Papermak Senri Ethnol Stud. 2013;85:61-81.

31. Koretsky E. Killing green: an account of hand papermaking in China. Oxford: The Legacy Press; 2009.

32. Inaba M, Chen G, Uyeda T, Katsumata K, Okawa A. The effect of cooking agents on the permanence of Washi (Part II). Restaurator. 2002;23:133-44.

33. Inaba M, Chen G, Uyeda T, Katsumata K, Okawa A. Permanence of Washi (Japanese paper). Restaurator. 2002;23:19-23.

34. Buchanan $S$, Coleman S. Deterioration survey of the stanford university libraries green library stack collection. In: Darling P, Boomgaarden W, editors. Preservation planning program resource notebook. Washington DC: Office of Management Studies; 1987. p. 159-91.

35. Havermans J, Dufour J. Photo Oxidation of paper documents: a literature review. Restaurator. 1997:18:103-14.

36. Begin P, Deschatelets S, Grattan D, Gurnagul N, Iraci J, Kaminska E, Woods D, Zou X. The Impact of lignin on paper permanence. A comprehensive study of the ageing behaviour of handsheets and commercial paper samples. Restaurator 1998:19:135-54.

37. May E, Jones M. Conservation science: heritage materials. Chapter 3. Cambridge: Royal Society of Chemistry Publishing: 2006.

38. Strlič M, Grossi CM, Dillon C, Bell N, Fouseki K, Brimblecombe P, Menart E, Ntanos K, Lindsay W, Thickett D, France F, De Bruin G. Damage function for historic paper. Part I: fitness for use. Herit Sci. 2015;3:33.

39. Strlič M, Grossi CM, Dillon C, Bell N, Fouseki K, Brimblecombe P, Menart E, Ntanos K, Lindsay W, Thickett D, France F, De Bruin G. Damage function for historic paper. Part II: wear and tear. Herit Sci. 2015;3:36. 
40. Stephens C, Barratt T, Whitmore P, Wade J, Mazurek J, Schilling M. Composition and condition of naturally aged papers. J Am Inst Conserv. 2008;47:201-15.

41. Strlič M, Cséfalvayováa L, Kolar J, Menart E, Kosek J, Barry C, Higgitt C, Cassar M. Non-destructive characterisation of iron gall ink drawings: not such a galling problem. Talanta. 2010;81:412-7.

42. Van den Akker JA, Lathrop AL, Voelker MH, Dearth LR. Importance of fiber strength to sheet strength. TAPPI. 1958;41:416-25.

43. Mark R, Habeger C. Handbook of physical testing of paper, vol. 1. Boca Raton: CRC Press; 2001.

44. Karlsson H. Strength properties of paper produced from softwood Kraft pulp. Karlstad University Studies. 2010;2010:15.

45. Varanasi S, Chiam HH, Batchelor W. Application and interpretation of zero and short-span testing on nanofibre sheet materials. Nord Pulp Pap Res J. 2012;27:343-51.
46. Vizarova K, Kirschnerova S, Kacik F, Briskarova A, Suty S, Katuscak S. Relationship between the decrease of degree of polymerization of cellulose and the loss of groundwood pulp paper mechanical properties during accelerated aging. Chem Pap. 2012;66:1124-9.

47. Martins A, Daffner LA, Fenech A, McGlinchey Ch, Strlič M. Non destructive dating of fiber base gelatin silver prints using near infrared spectroscopy and multivariate analysis. Anal Bioanal Chem. 2012:402:1459-69.

48. Fenech A, Strlič M, Cassar M. The past and the future of chromogenic colour photographs: lifetime modelling using near infrared spectroscopy \& enhancement using hypoxia. Appl Phys A. 2012;106:411-7.

49. Možir A, Strlič M, Trafela T, Kralj Cigić I, Kolar J, Deselnicu V, de Bruin G. On oxidative degradation of parchment and Its non-destructive characterisation and dating. Appl Phys A. 2011;104:211-7.

\section{Submit your manuscript to a SpringerOpen ${ }^{\circ}$ journal and benefit from:}

- Convenient online submission

- Rigorous peer review

- Open access: articles freely available online

- High visibility within the field

Retaining the copyright to your article

Submit your next manuscript at $\boldsymbol{\nabla}$ springeropen.com 